\title{
BMJ Open Direct and indirect costs of families with a child with acute lymphoblastic leukaemia in an academic hospital in China: a cross-sectional survey
}

\author{
Yijiong Ren, ${ }^{1}$ Xin $\mathrm{Li}^{2}$
}

To cite: Ren Y, Li X. Direct and indirect costs of families with a child with acute lymphoblastic leukaemia in an academic hospital in China: a crosssectional survey. BMJ Open 2019:9:e030511. doi:10.1136/ bmjopen-2019-030511

- Prepublication history and additional material for this paper are available online. To view these files, please visit the journal online (http://dx.doi. org/10.1136/bmjopen-2019030511).

YR and XL contributed equally.

Received 19 March 2019

Revised 17 June 2019

Accepted 28 June 2019
Check for updates

(c) Author(s) (or their employer(s)) 2019. Re-use permitted under CC BY-NC. No commercial re-use. See rights and permissions. Published by BMJ.

${ }^{1}$ Shanghai Children's Medical Center, School of Medicine,

Shanghai Jiao Tong University, Shanghai, China

${ }^{2}$ School of Social and Public Administration, East China University of Science and Technology, Shanghai, China

Correspondence to

Dr Xin Li; xinli@ecust.edu.cn

\section{ABSTRACT}

Objectives To estimate the direct and indirect costs in families with a child with acute lymphoblastic leukaemia (ALL) in China.

Design A single-site, cross-sectional survey of primary caregiver of a child with ALL was performed.

Setting and participants We analysed the total costs incurred on the completion of the first three-phase treatment (induction, consolidation and intensification), which requires intensive hospitalisation. Eligible patients were (1) diagnosed with ALL between 2010 and 2012 at Shanghai Children's Medical Center (SCMC), (2) aged 0-14 years at diagnosis and (3) completed the first three-phase treatment at SCMC. The data were collected between October 2014 and December 2014.

Outcome measures We decomposed the total costs into three categories: (1) direct medical costs, which were further divided into outpatient and inpatient costs; (2) direct non-medical costs, which referred to expenses incurred in relation to the illness; and (3) indirect costs due to productivity loss.

Results A total of 161 patients were included in the study. Direct medical costs accounted for about $51.7 \%$ of the overall costs, and the rest of $48.3 \%$ of the total costs were attributed to direct non-medical costs and indirect costs. Regarding families with different household registration type (rural vs urban), the total costs were significantly different between the two groups (US\$36 125 vs US\$25 $593 ; p=0.021)$. Specifically, urban families incurred significantly larger indirect costs than rural families (US\$12 343 vs US\$4157; $p=0.018$ ). Although the direct non-medical costs were not significantly different, urban families spent more money on hygiene cleaning products and auxiliary treatment equipment $(p=0.041)$ and gifts and treats $(p=0.034)$ than rural families.

Conclusions The financial burden faced by the Chinese families with a child with ALL was tremendous, and the distributions of costs among the three categories were different between urban and rural families.

\section{INTRODUCTION}

In China, the incidence of childhood cancer was 87.1 per million, and the mortality was 36.3 per million in $2010^{1}$. Acute lymphoblastic leukaemia (ALL) is the most common malignant disease among children, accounting for

\section{Strengths and limitations of this study}

- We estimated the direct and indirect costs in families with a child with acute lymphoblastic leukaemia in China.

- We decomposed the estimates of the total costs into three categories: direct medical costs, direct non-medical costs and indirect costs due to productivity loss.

- Majority cost measures were based on parents' self-report, and there might exist recall bias for some measures.

about $40 \%$ of all newly diagnosed childhood cancers. ${ }^{1}$ The 5 -year survival rate in childhood ALL has greatly increased over time and is now about $70 \%$ in China. ${ }^{1}$ Regardless of better survival, life-saving therapy is costly and may result in a financial burden for these patients' families. $^{2-7}$ On the one hand, the costs of treatment of ALL and illness-related expenses are immense; on the other hand, parents may have to reduce their work hours or give up paid work to care for their child resulting in loss of income.

Various studies have been conducted in developed countries to determine the costs associated with childhood cancer from a family perspective. $^{8}$ In these studies, the economic and financial impact of childhood cancer on families was examined on two primary cost categories: direct costs including the actual monetary expenditure related to the illness such as those associated with transport, food, accommodation and so on, ${ }^{34910}$ and indirect costs including the value of productivity loss such as cutting on work time, taking unpaid leave or quitting job. ${ }^{4-7}{ }^{11-13}$ Although it is hard to make a precise comparison of the magnitude of the financial costs of families due to variation in study design, all studies reported substantial family financial burden associated with childhood cancer treatment. 
Specifically, two Canadian studies found that income loss due to work disruption and out-of-pocket expenses were estimated at over $30 \%$ of after-tax family income, ${ }^{26}$ and one American study reported that over $50 \%$ of the poorest families experienced annual income loss of more than $40 \% .^{11}$

While childhood cancer was shown to have an adverse economic consequence on families in developed countries, it is likely to have even more severe effects in developing countries. In China, average treatment costs for childhood ALL were estimated to be between US\$15 128 and US\$45386, ${ }^{14}$ whereas per capita income was US $\$ 4270$ in 2018. Although the Chinese government has made great efforts to provide universal health coverage by the year 2010, the coverage is typically shallow. Overall, $65.1 \%$ of childhood ALL patients' insurance covered less than $50 \%$ of overall medical costs. ${ }^{14}$

Unfortunately, medical costs are not the only financial burden faced by the Chinese families, and the families with a child with ALL may also incur substantial additional costs associated with the illness. Specifically, there are huge differences in the allocation of medical resources between rural and urban areas and among different provinces. High-quality medical resources are mainly distributed in large central cities such as Beijing, Shanghai, Guangzhou and so on. Therefore, families with a seriously ill child have to go to these cities to receive treatment for a better chance of survival. As a result, the corresponding non-medical out-of-pocket expenses may increase dramatically due to extra expenditures on transport and accommodation. In addition, it is also hard for the parents to keep their jobs while taking care of the sick child, therefore resulting in loss of income.

In addition to unequal distribution of medical resources, there are significant differences between urban and rural areas in terms of income and social security system in China. In 2018, urban per capita income was more than 2.5 times of rural per capita income (US\$5938 vs US\$2211). Regarding the social security system, rural and urban populations are entitled to enrol in different health insurance schemes with different coverage plans, and unemployment and retirement insurances are only available to the urban working population. As a result, the economic burden is very likely to be different between rural and urban families.

As can be seen, the economic burden on Chinese families with a child with ALL could be devastated. Lacking financial aids from various sources may cause these families to fall from above to below the poverty line or even give up treatment. ${ }^{14}$ However, research on determining the costs associated with a childhood ALL is rare, and the nature of these costs is poorly understood in developing countries. ${ }^{15-18}$ It makes policy planning in the context of essential medicines, national fiscal policy towards childhood ALL and donor policy difficult without any reliable estimates of costs. The purpose of this paper was to estimate the economic burden in families with a child with ALL in China. In addition, we also reported the total costs and its three components for rural and urban families separately.

\section{METHODS}

\section{Data and study population}

The treatment of childhood ALL usually has four phases: induction, consolidation, intensification and maintenance and lasts 2-3 years ${ }^{19}$. In the present paper, we estimated total costs incurred on the completion of the first three-phase treatment (induction, consolidation and intensification), which requires intensive hospitalisation. Therefore, eligible patients were (1) diagnosed with ALL between 2010 and 2012 at Shanghai Children's Medical Center (SCMC), (2) aged 0-14 years at diagnosis and (3) completed the first three-phase treatment at SCMC. The data were collected between October 2014 and December 2014. The time between diagnosis and completion of the questionnaire was required to be greater than 2 years in order to capture parents' employment experiences throughout the treatment. Since quite a lot of the families were not living in Shanghai, face-to-face interviews were difficult to conduct. As an alternative, we conducted telephone interviews on the parents. Only one parent of the child, who self-identified as the major caregiver of the child answered the questionnaire. The interview lasted about 30-45 min. We obtained approval from the Institutional Review Board of SCMC to conduct the study.

\section{Pretesting}

In order to ensure the rationality and accuracy of the questionnaire, we pretested the questionnaire with 15 parents with a child with ALL who were randomly picked during their follow-up visits to the centre. During this period, we revised the questionnaire many times to make sure that parents understood the questions, did not feel uncomfortable and were aware of their costs reflecting the costs incurred during the induction, consolidation and intensification phases, not the costs associated with the maintenance therapy.

\section{Measures}

We decomposed the costs into three categories: (1) direct medical costs, which were further divided into outpatient and inpatient costs; (2) direct non-medical costs, which referred to expenses incurred in relation to the illness; and (3) indirect costs due to productivity loss.

A structured questionnaire survey tool was developed (online supplementary file) to collect data. The questionnaire included three modules. The first module asked questions about sociodemographic characteristics of parents and their child. The second module included direct non-medical cost questions. The last module focused on indirect cost questions. More specifically, the details of these modules were shown as follows:

Demographic and socioeconomic variables: child age at diagnosis, child gender and whether child had health insurance, parent's age at diagnosis, the highest degree of 
parental education (elementary or lower, high/vocational school or lower or college and above), family monthly income, family size, household registration type (Hukou types: rural vs urban) and place of residence (Shanghai vs other provinces).

Direct non-medical cost variables: direct non-medical costs included expenses related to illness during the period of the first three stages of treatment. Specifically, parent was asked to provide information on (1) expenses on accommodation per month including rent and utility fee; (2) expenses on transportation; (3) increased expenses on food and nutritional supplements per month; (4) expenses on hygiene cleaning products and auxiliary treatment equipment, such as ultraviolet disinfection lamp, air purifier and humidifier; and (5) expenses on gifts and treats including electrical devices (eg, computer, TV and video games) and network fee.

Indirect cost variables: indirect costs were the costs associated with lost productivity due to illness. In the present paper, parent was asked to provide information on employment status at diagnosis and during the treatment period, changes in role or hours worked since diagnosis and length of absence from work. Informant was also asked to complete this section for his or her partner. The indirect costs were measured by lost earnings using the human capital approach.

Direct medical cost variables: The computerised database of medical costs at SCMC was established in 1998. The database strictly adheres to medical administration regulations. According to the administration system, all medicines and blood products should be supplied by the department of pharmacy and blood bank at SCMC. All lab tests and non-lab tests (including electroencephalogram, electrocardiogram and various diagnostic imaging) should be done at SCMC as well. All outpatient and hospitalisation costs were recorded according to their names/ case numbers. In the present paper, overall outpatient and inpatient costs for each child with ALL between the confirmation of diagnosis at SCMC and the completion of the intensification therapy were collected from the database. The components of costs included costs for western medicine, Chinese medicine, blood products, lab tests, non-lab tests, hospital bed/daycare and consultant fees, using the nursing injection facility and consumption of materials and oxygen. In addition, the database also contained information on inpatient expenses paid by insurance for local patients.

\section{Patient and public involvement}

No patients were involved in the development of the research question, the outcome measures, the design or implementation of the study. There are no plans about the dissemination of the results.

\section{Statistical analysis}

All data were reviewed for completeness and relevance. Data were entered into Microsoft Excel and imported into the STATA 13 statistical package (Stata Corporation) for analysis. Descriptive statistics were used to describe the sample characteristics and categorise the types and values of cost categories and items. The $\chi^{2}$ tests and the t-tests were used for bivariate comparisons of categorical and continuous variables for the urban and rural families, respectively. The amounts of all cost categories were projected to the estimates that incurred during the treatment. We expressed all cost estimates in $2010 \mathrm{RMB}$ using the Consumer Price Index and then converted in US\$ using the average exchange rate between RMB and US\$ in 2010 (US\$1.00=RMB 6.7695). Total costs were then computed as the sum of all cost categories for the sample. T-tests were used to examine the rural versus urban differences in all cost estimates. A two-tailed $\mathrm{p}$ value of 0.05 was considered statistically significant.

\section{RESULTS}

Medical expenses and parental contact information of a total of 171 patients were extracted from the SCMC database. We contacted the 171 parents using the telephone numbers provided in the database, and 161 parents gave the consent before we conducted the interview. The 10 failed calls were due to either loss of contact or refuse to participate.

Table 1 presents the child, parent and family characteristics for the whole sample and for the urban and rural subsamples. The mean patient age at diagnosis was 4.9 years ( $\mathrm{SD}=3.3$ years; range: $0-14$ years), and the majority were men $(58.4 \%)$. The average length of therapy (induction, consolidation and intensification) was 11.6 months ( $\mathrm{SD}=9.6$ months). Fifty-two patients $(33.1 \%)$ did not have any insurance at the time of diagnosis. The mean age of parents at diagnosis was 33.2 years ( $\mathrm{SD}=4.3$ years), and the majority of the parents' highest education level was high/vocational school or below (61.9\%). In terms of household characteristics, the average family size was 4.1 ( $\mathrm{SD}=1.1$ ), 71 households $(44.1 \%)$ had rural registration and only 33 households (20.6\%) were local residents (Shanghai). The average household monthly income at diagnosis was US\$1232.25. Regarding urban and rural families, the highest education for parents in an urban area was significantly higher than that of parents from a rural area $(\mathrm{p}<0.001)$. In addition, urban families had smaller family size $(\mathrm{p}<0.001)$, higher monthly income $(p=0.02)$ and were more likely to be local residents $(\mathrm{p}<0.001)$ than their rural counterparts.

Table 2 describes the parents' employment statuses at the time of diagnosis and during the treatment period. On diagnosis, 35 (22\%) fathers worked in government, stateowned enterprise (SOE) or public sector, 109 (68.6\%) worked in private sector or self-employed, 11 (6.9\%) were farmers, and 4 (2.5\%) were unemployed. During the treatment, 47 working fathers managed to keep their employment status unchanged, 13 completely stopped working, and 97 reported to take extended absences from work. The average length of absences was 14.4 months ( $\mathrm{SD}=11.1$ months). Regarding mothers, on diagnosis, 32 
Table 1 Child, parent and family characteristics $(n=161)$

\begin{tabular}{|c|c|c|c|c|}
\hline Characteristics & Total $(\mathrm{N}=161)$ & Urban $(n=90)$ & Rural ( $n=71)$ & $P$ value \\
\hline \multicolumn{5}{|l|}{ Child } \\
\hline Age at diagnosis, years (mean, SD) & $4.9(3.3)$ & $4.7(3.2)$ & $5.1(3.3)$ & 0.48 \\
\hline $\begin{array}{l}\text { Average treatment period, months (mean, } \\
\text { SD) }\end{array}$ & $11.6(9.6)$ & $12.4(10.4)$ & $10.6(8.5)$ & 0.25 \\
\hline \multicolumn{5}{|l|}{ Gender, n (\%) } \\
\hline Male & 94 (58.4) & $54(60.0)$ & $40(56.3)$ & 0.64 \\
\hline Female & $67(41.6)$ & $36(40.0)$ & $31(43.7)$ & \\
\hline No Health insurance & $52(33.1)$ & $32(35.5)$ & $20(28.1)$ & 0.33 \\
\hline \multicolumn{5}{|l|}{$\begin{array}{l}\text { Parents } \\
\text { Age at diagnosis, years (mean, SD) }\end{array}$} \\
\hline $\begin{array}{l}\text { Education (the highest degree of parental } \\
\text { education), } \mathrm{n}(\%)\end{array}$ & $33.2(4.3)$ & $33.6(4.4)$ & $32.8(4.7)$ & 0.34 \\
\hline Middle school or lower, n (\%) & $67(41.9)$ & $18(20.0)$ & $50(70.4)$ & $<0.001$ \\
\hline High/vocational school , n (\%) & $32(20.0)$ & $17(18.9)$ & $15(21.1)$ & \\
\hline College or above, $\mathrm{n}(\%)$ & $61(38.1)$ & $55(61.1)$ & $6(8.5)$ & \\
\hline \multicolumn{5}{|l|}{ Household } \\
\hline Family size (mean, SD) & $4.1(1.1)$ & $3.8(0.9)$ & $4.5(1.1)$ & $<0.001$ \\
\hline $\begin{array}{l}\text { Household monthly income, US\$ (mean, } \\
\text { SD) }\end{array}$ & $1287.31(2518.36)$ & $1681.56(3082.12)$ & 783.35 (1379.65) & 0.02 \\
\hline \multicolumn{5}{|l|}{ Area of residence, $\mathrm{n}(\%)$} \\
\hline Shanghai & $33(20.6)$ & 30 (33.3) & $3(4.2)$ & $<0.001$ \\
\hline Other provinces & $128(79.4)$ & $60(66.7)$ & $68(95.8)$ & \\
\hline
\end{tabular}

$(20.1 \%)$ worked in government, SOE or public sector, 73 (45.9) worked in private sector or self-employed, 16 $(10.1 \%)$ were farmers, and 38 (23.9\%) were unemployed or doing housework. Among those who had a job, 14.8\% did not change their employment status, $6.6 \%$ stopped working, and the majority of working mothers $(78.7 \%)$ took extended absences from work. The average length of absences was 18.1 months ( $\mathrm{SD}=10.8$ months).
The three categories of the total costs and their components for the whole sample are given in table 3 . Panel A reported that the average total medical costs during the treatment were US\$16 307 (SD=14488; IQR 9441-18 120). Medical costs were then divided into two subcategories: outpatient and inpatient costs. The inpatient costs accounted for the majority of the total medical costs $(66.9 \%)$. Panel B of table 3 presents the

\begin{tabular}{|c|c|c|c|c|}
\hline Characteristics & $\mathbf{n}$ & $\%$ & $\mathbf{n}$ & $\%$ \\
\hline Employment at diagnosis & Father & & Mother & \\
\hline Government, SOE, or public sector & 35 & 22.0 & 32 & 20.1 \\
\hline Private sector or self-employed & 109 & 68.6 & 73 & 45.9 \\
\hline Agriculture & 11 & 6.9 & 16 & 10.1 \\
\hline Unemployed or doing housework & 4 & 2.5 & 38 & 23.9 \\
\hline $\begin{array}{l}\text { Change of employment status (conditional on } \\
\text { employed at diagnosis) }\end{array}$ & Father & & Mother & \\
\hline No change & 47 & 29.9 & 18 & 14.8 \\
\hline Completely stop working & 13 & 8.3 & 8 & 6.6 \\
\hline Extended leave & 97 & 61.7 & 96 & 78.7 \\
\hline Average length of absence, months (mean, SD) & 14.4 & 11.1 & 18.1 & 10.8 \\
\hline
\end{tabular}

SOE, state-owned enterprise. 
Table 3 Total cost and its components (in 2010 US\$)*

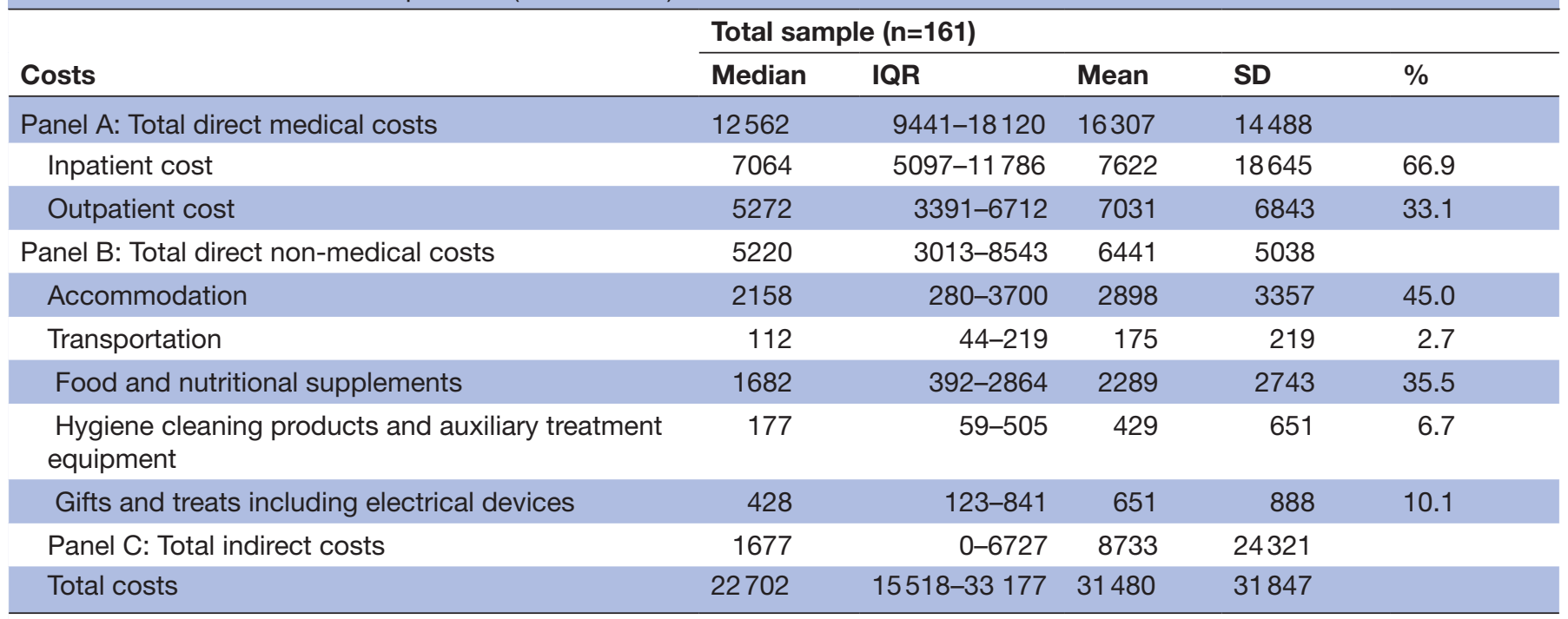

*The average exchange rate between RMB and US\$ in 2010 is 6.7695 .

direct non-medical costs incurred during the treatment. The average direct non-medical costs were US $\$ 6441$ ( $\mathrm{SD}=5038$; IQR 3013-8543) with the largest expenditure on accommodation. The average indirect costs incurred during the treatment (Panel C of table 3) were estimated to be USD 8733 ( $\mathrm{SD}=24321$; IQR 0-6727). On average, the total costs for the whole sample were US\$31 480 ( $\mathrm{SD}=31$ 847; IQR 15518-33 177). The direct medical costs accounted for more than half of the total costs (51.8\%), followed by indirect costs $(27.7 \%)$ and direct non-medical costs $(20.5 \%)$.

Table 4 reports the total costs and their components for rural and urban families, respectively. The total costs were significantly different between the two groups (mean: US $\$ 36125$ vs US $\$ 25$ 592; $\mathrm{p}=0.021$ ). Regarding the three cost categories, the urban families incurred significantly larger indirect costs than the rural families (mean: US $\$ 12343$ vs US $\$ 4157 ; p=0.018$ ). Although the direct non-medical costs were not significantly different, the urban families spent more money on hygiene cleaning products and auxiliary treatment equipment $(\mathrm{p}=0.041)$ and gifts and treats $(\mathrm{p}=0.034)$ than the rural families.

\section{DISCUSSION}

A cancer diagnosis in childhood can substantially affect the physical, psychosocial, and socioeconomic well-being of patients and their families. Yet, research on determining the costs associated with a childhood ALL is rare, and the nature of these costs is poorly understood, especially in developing countries. The present study provides a breakdown of families' costs and resource use and an in-depth understanding of families' financial burden. We found that the financial burden faced by Chinese families with a child with ALL was tremendous. Among the three cost categories, direct medical costs accounted for about $51.8 \%$ of the overall costs, and the rest of $48.2 \%$ of the total costs were attributed to direct non-medical costs and indirect costs. Regarding families with different household registration type (rural vs urban), the distributions of costs among the three categories were different. Productivity loss contributed a much higher weight in total costs for urban families than for rural families. In addition, rural families spent most of their money on the treatment of ALL.

Our results showed that the average medical costs were approximately US $\$ 16307$, which were comparable to the findings from previous studies using data of developing countries. ${ }^{14} 1520$ Unlike most developed countries where costs of treatment are borne mainly by the public sector and health insurance, ${ }^{413}$ patients in developing countries have to bear a significant portion of direct medical costs. ${ }^{16}{ }^{17}$ According to the health insurance regulations of China, if patient chooses to receive treatment in other province or city or in non-designated hospital, the reimbursement rate could be very low or none at all. Although we were unable to determine this from our study directly, one report did have shown that the actual reimbursement rate was less than $50 \%$ for most of the rural families with a child with leukaemia, of which around $27 \%$ of children only got $30 \%$ of reimbursement. ${ }^{14}$ In addition, in the questionnaire we asked 'any comments or suggestions on current insurance reimbursement policy?', more than half of the non-local parents $(57.8 \%$; data not shown) mentioned that the reimbursement rate was too low. Specifically, they identified the low reimbursement mainly due to the following reasons: there existed a big gap on reimbursement rate between local and non-local residents; outpatient and imported medicines were not covered by the insurance, and the reimbursement procedure across provinces was tedious and time consuming, and the actual reimbursement rate was low, so some parents chose to forgo reimbursement. 


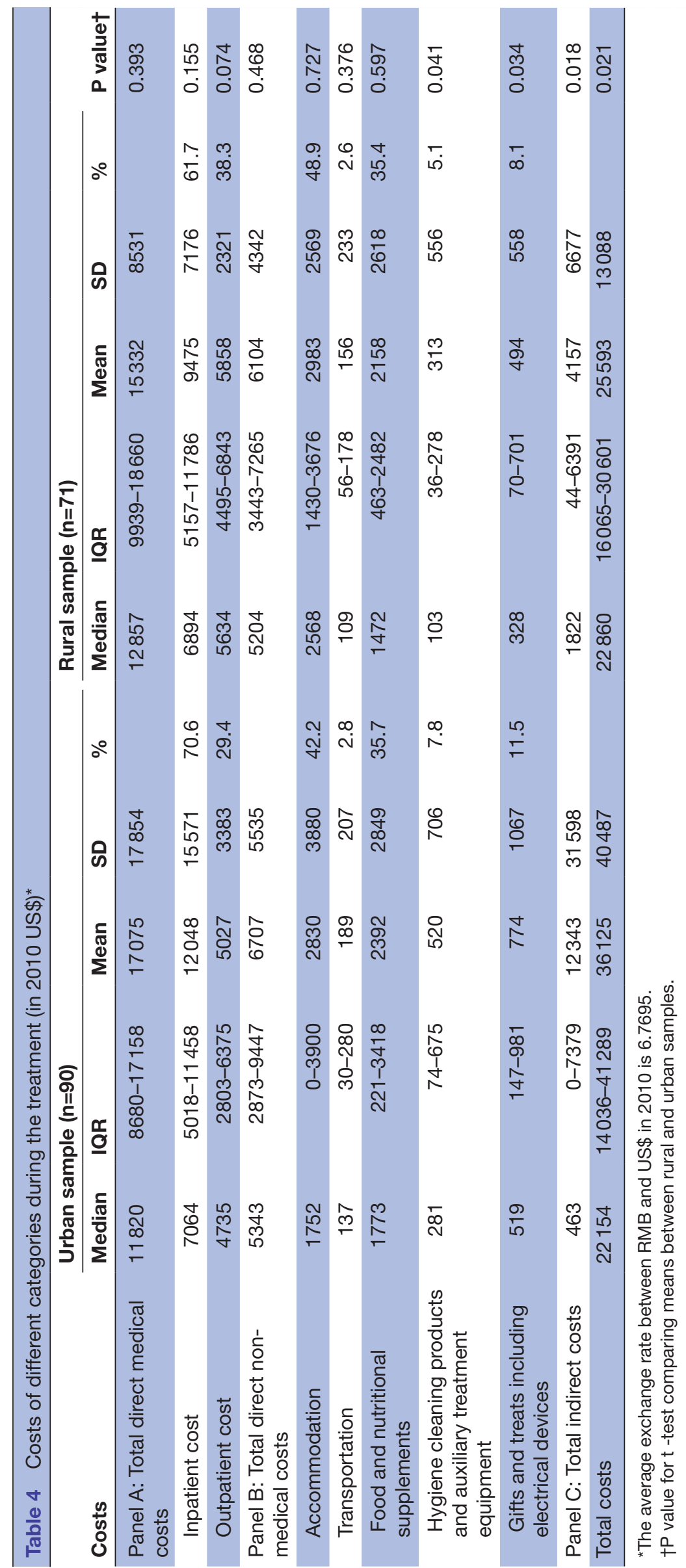

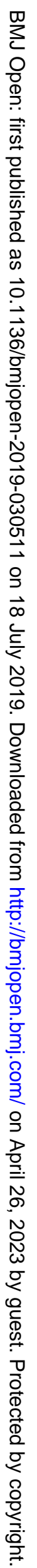


In contrast to the previous literature which found that transport took a significant portion of family financial cost, ${ }^{91021}$ our results showed that transport only contributed to $2.7 \%$ of the total direct non-medical costs, whereas around $45 \%$ of the total direct non-medical expenses were spent on accommodation. That was because most of the non-local families chose to rent near the hospital, which saved travel costs. Although the very poor families can receive 30 days of accommodation at the centre at very low price, ${ }^{15}$ space is limited, and the 30 day rental period is far from enough. Most non-local families had to rent a room or an apartment near the hospital for about US\$146.02-US\$730.09 per month for an average of 12 months. Food and nutritional supplements accounted for about $35 \%$ of the total direct non-medical cost. As described by Tsimicalis et $\mathrm{al}^{10}$, increased expenses on food were to accommodate the child's fluctuating weight, satisfy food cravings, and taste alterations.

Following diagnosis, $85 \%$ of working mothers and $70 \%$ of working fathers gave up all paid employment or took unpaid extended leaves in our sample. These numbers were much higher than those reported in the previous studies. ${ }^{461213}$ The possible explanation was that in our sample, the majority families were from other provinces $(79 \%)$, and it was hard for only one parent to handle all the issues related to treatment, accommodation, and food; therefore, both parents had to quit their jobs or took unpaid leaves during the treatment.

Our data indicated that families with high socioeconomic status were more likely to receive treatment in highquality medical facilities. Specifically, according to data from the National Bureau of Statistics of China, in 2010, the annual urban per capita income was US $\$ 2822.87$, and the amount was RMB874.36 in the rural areas. ${ }^{22}$ However, our data indicated that the sample urban per capita income (was calculated as urban household monthly income $\chi 12$ /family size, using the data from table 1) was 1.9 times that of the national urban average, and the ratio became 2.4 times for the rural per capita income. In addition, our data showed that the total costs were 1.79 times of the sample urban family's annual income and were 2.72 times of the sample rural family's annual income. This finding indicated that even for these high socioeconomic families, the economic burden of childhood ALL was huge, especially for rural families.

Our findings have very important policy implications. First, policymakers should make effort on simplifying the reimbursement procedure across provinces and eliminating the huge disparities in reimbursement ratio across regions; second, our sample indicated $33 \%$ of patients did not have any insurance at diagnosis, although we did not have direct data on why these parents chose not to purchase insurance for their child, previous study has shown that lack of knowledge or the concept of insurance could be a major barrier for people from participating the insurance program $;{ }^{23}$ therefore, the government should work hard on educating people regarding the different programmes; third, patients with cancer and their families may need ongoing financial management with a designated financial advisor well beyond the initial treatment phase to help them manage debt, access resources to cope with direct and indirect costs of cancer treatment and maintain patients' and families' financial capacity later in life.

There are limitations to this study. First, majority measures were based on parents' self-report, and there may exist recall bias for some measures. However, to minimise recall bias, before conducting a formal interview, we contacted them 1 week in advance and asked parents to recall and list out the details of all the expenses during the treatment. After the interview, we double checked data. If there was inconsistency in the data, we called back to clarify. Second, while the generalisability of this study may be somewhat limited as we focused on one hospital, SCMC, as one of the primary paediatric tertiary care centres in China, it provides treatment of severe disease in children around China (our data showed that $79 \%$ of patients were non-local residents). Therefore, our results are likely applicable to other geographic areas. Third, our sample included the families who were relatively rich compare with the national average, which limited our ability to assess the financial impact among the families with low socioeconomic status.

Families of children with ALL experience a wide range of costs. An ongoing investigation of families' costs will yield a rich understanding of the disease costs, formulate the basis of cost assessments, and lend insight into practice and policy changes aimed at lessening the economic impact of this burden.

Contributors YR and XL designed the study, developed a data analysis plan and equally contributed to this study. XL performed a statistical analysis of the data. All authors made significant contributions to the interpretation of results and participated in drafting and revising the manuscript. All authors have approved the final version.

Funding This work was supported by the Fundamental Research Funds for the Central Universities of China (Grant No. 17JCYA03).

Competing interests None declared.

Patient consent for publication Not required.

Ethics approval This study was approved by the Institutional Review Board of Shanghai Children's Medical Center.

Provenance and peer review Not commissioned; externally peer reviewed.

Data sharing statement № additional data are available.

Open access This is an open access article distributed in accordance with the Creative Commons Attribution Non Commercial (CC BY-NC 4.0) license, which permits others to distribute, remix, adapt, build upon this work non-commercially, and license their derivative works on different terms, provided the original work is properly cited, appropriate credit is given, any changes made indicated, and the use is non-commercial. See: http://creativecommons.org/licenses/by-nc/4.0/.

\section{REFERENCES}

1. Zheng $\mathrm{R}$, Peng X, Zeng $\mathrm{H}$, et al. Incidence, mortality and survival of childhood cancer in China during 2000-2010 period: A populationbased study. Cancer Lett 2015;363:176-80.

2. Barr R, Furlong W, Horsman J, et al. The monetary costs of childhood cancer to the families of patients. Int $J$ Oncol 1996;8:933-40. 
3. Dockerty JD, Skegg DC, Williams SM. Economic effects of childhood cancer on families. J Paediatr Child Health 2003;39:254-8.

4. Eiser C, Upton P. Costs of caring for a child with cancer: a questionnaire survey. Child Care Health Dev 2007;33:455-9.

5. Dussel V, Bona K, Heath JA, et al. Unmeasured costs of a child's death: perceived financial burden, work disruptions, and economic coping strategies used by American and Australian families who lost children to cancer. J Clin Oncol 2011;29:1007-13.

6. Tsimicalis A, Stevens B, Ungar WJ, et al. A prospective study to determine the costs incurred by families of children newly diagnosed with cancer in Ontario. Psychooncology 2012;21:1113-23.

7. Warner EL, Kirchhoff AC, Nam GE, et al. Financial Burden of Pediatric Cancer for Patients and Their Families. J Oncol Pract 2015;11:12-18.

8. Pelletier W, Bona K. Assessment of Financial Burden as a Standard of Care in Pediatric Oncology. Pediatr Blood Cancer 2015;62(Suppl 5):S619-31.

9. Cohn RJ, Goodenough B, Foreman T, et al. Hidden financial costs in treatment for childhood cancer: an Australian study of lifestyle implications for families absorbing out-of-pocket expenses. J Pediatr Hematol Oncol 2003;25:854-63.

10. Tsimicalis A, Stevens B, Ungar WJ, et al. A mixed method approach to describe the out-of-pocket expenses incurred by families of children with cancer. Pediatr Blood Cancer 2013;60:438-45.

11. Bona K, Dussel V, Orellana L, et al. Economic impact of advanced pediatric cancer on families. J Pain Symptom Manage 2014; 47:594-603.

12. Fluchel MN, Kirchhoff AC, Bodson J, et al. Geography and the burden of care in pediatric cancers. Pediatr Blood Cancer 2014;61:1918-24.

13. Limburg H, Shaw AK, McBride ML. Impact of childhood cancer on parental employment and sources of income: a Canadian pilot study. Pediatr Blood Cancer 2008;51:93-8.
14. Report RC. A report on the living conditions of children diagnosed with leukemia in rural China. 2013. Available at https://wenku.baidu. $\mathrm{com} /$ view/7004a99b4afe04a1b071 dec5.html.

15. Liu Y, Chen J, Tang J, et al. Cost of childhood acute lymphoblastic leukemia care in Shanghai, China. Pediatr Blood Cancer 2009;53:557-62.

16. Islam A, Akhter A, Eden T. Cost of treatment for children with acute lymphoblastic leukemia in Bangladesh. $J$ Cancer Policy 2015;6:37-43.

17. Ghatak N, Trehan A, Bansal D. Financial burden of therapy in families with a child with acute lymphoblastic leukemia: report from north India. Support Care Cancer 2016;24:103-8.

18. Wang J, Shen N, Zhang X, et al. Care burden and its predictive factors in parents of newly diagnosed children with acute lymphoblastic leukemia in academic hospitals in China. Support Care Cancer 2017;25:3703-13.

19. Seibel NL. Treatment of acute lymphoblastic leukemia in children and adolescents: peaks and pitfalls. Hematology Am Soc Hematol Educ Program 2008;1:374-80.

20. Bhakta N, Martiniuk AL, Gupta S, et al. The cost effectiveness of treating paediatric cancer in low-income and middle-income countries: a case-study approach using acute lymphocytic leukaemia in Brazil and Burkitt lymphoma in Malawi. Arch Dis Child 2013;98:155-60.

21. Miedema B, Easley J, Fortin P, et al. The economic impact on families when a child is diagnosed with cancer. Curr Oncol 2008;15:93-8.

22. National Bureau of Statistics of China. Data. 2011. available at http:// www.stats.gov.cn/tjsj/ndsj/2011/indexch.htm.

23. Li X, Zhang W. The impacts of health insurance on health care utilization among the older people in China. Soc Sci Med 2013;85:59-65. 